\title{
Universos do conhecimento. Reflexões sobre a investigação narrativa na educação
}

\author{
Gabriela Cruz Vásquezi
}

Universidad Autónoma de Baja California, México

Adriana Pastorello Buim Arenaii

Universidade Federal de Uberlândia, Brasil

\section{Resumo}

O presente texto tem como objetivo oferecer ao leitor alguns apontamentos dos conceitos que envolvem a temática da investigação narrativa em educação e na pesquisa qualitativa. Quando se discute sobre esta modalidade de fazer investigação, há sempre dúvidas quanto a sua validade, geradas pela forte tradição positivista que predomina desde o nascimento do método científico. Com a intenção de complexificar a discussão sobre a natureza da pesquisa qualitativa, educativa e narrativa, este trabalho apoia-se em autores que problematizam os termos experiência, tempo, espaço, palavra e investigação narrativa, a partir da investigação e da literatura. Nas conclusões faz-se uma reflexão sobre a investigação narrativa como um giro metodológico qualitativo que possibilita uma rica geração de dados para o entendimento e a interpretação de níveis mais profundos da complexa subjetividade humana e da prática educativa.

Palavras-chave

Experiência; Tempo-Espaço; Palavra; Investigação narrativa 


\section{Introdução}

Quantos silêncios, quantas histórias, quantos universos ainda perdidos.

Há dois conceitos muito usados na pesquisa em educação com a intenção de situar o objeto de estudo, mas nem sempre devidamente explorados no campo científico: o tempo e o espaço. Tradicionalmente, prioriza-se 0 estudo desses conceitos na Filosofia, com o intuito de decifrálos, como o fez Santo Agostinho no livro XI das Confissões - O homem e o Tempo (1973), mas ainda há muito que se pensar e refletir sobre essas palavras, aparentemente tão simples de compreender, quando se pensa na máquina do relógio ou na divisão geográfica apresentada pelo mapa mundi. Ao estudar o problema do tempo sob o aspecto psicológico, diz Santo Agostinho (1973): "O que é, por conseguinte o tempo? Se ninguém me perguntar, eu sei; se o quiser explicar a quem me fizer a pergunta, já não sei" (p. 244). O filósofo expressa toda a complexidade envolvida na construção de uma resposta convincente.

Também é possível encontrar essa discussão filosófica na literatura. Ao mencionar os termos tempo e espaço, é possível que o leitor se recorde de um dos contos mais breves e indecifráveis da literatura universal, $O$ livro de areia (Borges, 2012), do escritor argentino Jorge Luis Borges (1899-1986). Como encontrar uma interpretação contundente e definitiva para estas palavras apresentadas no texto? "Se o espaço é infinito, estamos em qualquer ponto do espaço; se o tempo é infinito, estamos em qualquer ponto do tempo" (p. 92). Neste breve excerto, um livro com folhas e símbolos sem princípio e sem fim, como a areia, converte-se em um artefato monstruoso capaz de corromper a realidade. Seria preferível, segundo o autor desse conto, desconhecer a infinitude do tempo e do espaço, isto é, conceber somente o finito. O memorável conto de Jorge Luis Borges foi apresentado em razão do enigma desses dois conceitos - infinidades do espaço e do tempo - em distintas áreas de estudo, e, no caso deste trabalho, na educação, especificamente nas investigações narrativas. Decidiu-se correr o risco de levar a cabo uma analogia entre o tema da investigação narrativa abordado nos textos de Benjamin (1985), Connelly e Clandinin (1995), Guimarães (2006), Guimarães e Guimarães (2011), Larrosa (2002) e o tema da infinitude do tempo e do espaço na obra $O$ livro de areia de Borges. Os mistérios do 
tempo e do espaço abordados com base na investigação educativa e narrativa e na ficção narrativa constituem o âmago deste texto.

Com esta escolha, pretende-se discutir as implicações desses conceitos - ainda não suficientemente claros - na investigação narrativa em educação e, quiçá, ampliar um pouco mais esse debate. O trabalho se apresentará em duas partes. Na primeira, tem-se como objetivo sintetizar o conhecimento teórico e metodológico dos temas experiência, conhecimento e investigação narrativa abordados por diversos autores. Na segunda, será apresentada uma analogia criativa entre a supracitada síntese e a obra $O$ livro de areia. Tem-se ainda como objetivo geral defender o ponto de vista de que a narrativa, com seus espaços e seus tempos, é uma extraordinária metodologia de geração de dados em pesquisa de natureza qualitativa.

\section{Experiência, conhecimento e investigação narrativa}

Silêncio, tempo, espaço e palavra. Como nas sinfonias, esses elementos se entrelaçam na investigação narrativa, não podem se desvincular uns dos outros, e nos meandros de cada um deles há conceitos ocultos, alinhavados, imperceptíveis, mas presentes para a construção de significados, de realidades, de mundos humanos e sociais. Nomeia-se primeiramente o silêncio porque, juntamente com o tempo e o espaço, fecunda a palavra, que é parte dele. O silêncio vem primeiro, início do todo, dos significados; trata-se de um conceito que foi praticamente esquecido, não percebido ou ignorado. No entanto, na investigação educativa, antes que os pesquisadores iniciem seu trabalho sobre uma realidade determinada, tudo é primeiramente silêncio, em seu estado puro.

Assim, primeiro vem o silêncio. Em seguida, o tempo e o espaço. Por fim vem a palavra na qual se cristalizam as narrativas. Depois, os investigadores educativos - os cientistas - tentam uma amalgamação que, em vez de extrair metais nobres, busca compreender e interpretar uma parte da realidade. A palavra e as narrativas parecem então compor-se de infinitos significados e mistérios.

A escolha deste tema não se deu ao acaso. Ela é o reflexo da opção teórica dos autores deste trabalho e de suas experiências vividas, ou até mesmo da proximidade com a narrativa, para articular uma discussão sobre a 
teoria e a metodologia deste tipo de investigação. Quiçá esta reflexão seja também um processo de converter-se em pessoa, lembrando Rogers (1991), para quem a própria experiência influi de maneira significativa no que o indivíduo descobre, incorpora, assimila, compreende e interpreta.

A importância da produção de conhecimento mediante a investigação narrativa, como outras abordagens teóricas e metodológicas, reside na realização de "um ato de criação de conhecimento novo, um processo que faça avançar a ciência na área" (Severino, 2002, p. 69), neste caso, no campo educacional, ainda que sem a aspiração de caminhos para uma verdade provisória, por tratar-se, especificamente, de termos de investigação narrativa e qualitativa, de um exercício interpretativo.

Um dos aspectos que parece mais memorável das origens da tradição da investigação qualitativa na educação, no século XIX, é a ideia constante de conceber este enfoque como um meio para combater o sofrimento e a pobreza humana (Bogdan \& Biklen, 1994). Não se concebe ainda a existência desse remédio absoluto ou parcial para tão nobre objetivo, sabendo-se que os próprios cientistas são também parte desta humanidade doente. Entretanto, deve ter-se sempre presente que a busca desse remédio, ao qual com afã aspiravam Le Play (1806-1882) - ilustre economista francês - e outros investigadores do século XIX, foi um dos objetivos que, ao fazer parte das origens da investigação qualitativa, segue implícito nos avanços dessa forma de ver o mundo, quer dizer, nas abordagens teóricas e metodológicas qualitativas.

$\mathrm{Na}$ realidade, poder-se-ia iniciar a síntese reflexiva com os autores selecionados para abordar o tema da investigação narrativa, como Benjamin (1985), Connelly e Clandinin (1995), Guimarães (2006), Guimarães e Guimarães (2011), Larrosa (2002) ou, para a ficção narrativa, Borges (2012). Mas ela não será feita desta maneira. Mostrar-se-á, primeiramente, uma das gravuras que ilustram o livro L'atmosphère: Météorologie populaire (1888) do astrônomo francês Camile Flammarion (1842-1925) (Figura 1), cuja escolha será explicada somente no final deste texto. Por ora, ela somente será apresentada, para que os leitores possam interpretá-la livremente. 


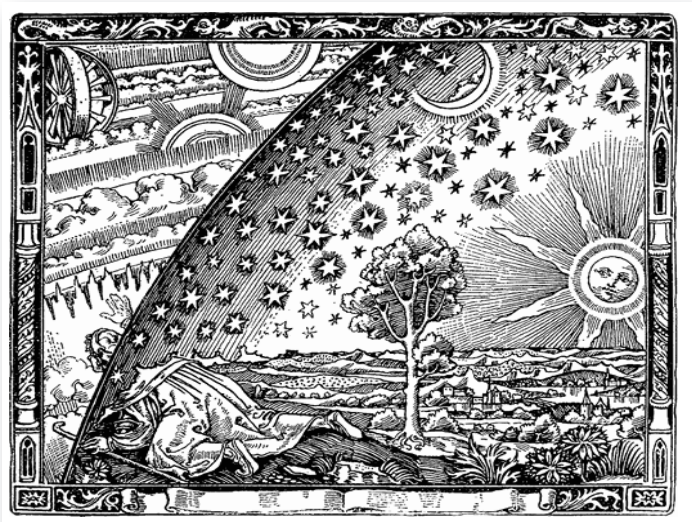

Figura 1 - Anônimo. Un missionnaire du moyen âge raconte qu'il avait trouvé le point où le ciel et la Terre se touchent. [Ilustração]

(Flammarion, 1888, p. 163)

Esta ilustração, de autor desconhecido, aparece no livro de Flammarion (1888) com a seguinte legenda: "um missionário da Idade Média conta que encontrou o ponto onde o céu e a terra se tocam". O título do livro, A atmosfera: Meteorologia popular, e o título da ilustração, na obra original, foram os elementos que motivaram esta escolha por parte das autoras deste texto. Resta agora ao leitor emitir sua apreciação. Mais adiante, o conteúdo aqui apresentado deverá fazer sentido no conjunto dos temas aqui abordados.

Voltemos à questão central do trabalho, após termos levantado hipóteses diversas a partir da contemplação da figura apresentada por Flammarion, sobre o conhecimento e a ciência. A questão que se coloca, em primeiro lugar, é compreender se a investigação narrativa pode ser útil ou não à ciência. Enquanto a ciência aspira à construção de uma compreensão dos seres humanos, da natureza e das relações humanas por meio de "um conjunto estruturado de conhecimentos que nos permita compreender em profundidade aquilo que, à primeira vista, o mundo das coisas e dos homens nos revela nebulosamente ou sob uma aparência caótica" (Gatti, 2007, p. 10), a investigação narrativa estuda como os seres humanos experimentam o mundo, quer dizer, ela caracteriza os fenômenos da experiência humana 
vivida para sua aplicação na experiência educativa, isto é, o valor central desta linha de investigação é a geração de temas novos sobre a relação teoria-prática no ensino e na aprendizagem (Connelly \& Clandinin, 1995). Com base nessas duas aproximações, investigação narrativa e ciência, podese intuir que a aspiração ao estudo da interação social, ao diálogo entre os sujeitos em um tempo e em um espaço, é o que une investigação narrativa e ciência.

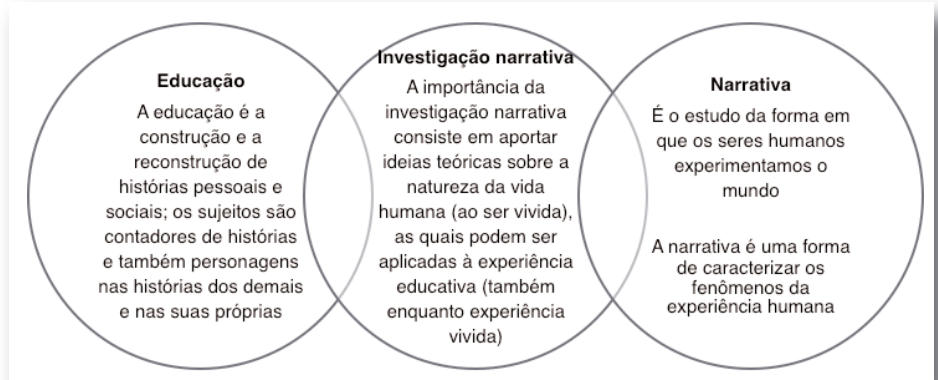

Figura 2 - Investigação narrativa e educação (baseado em Connelly \& Clandinin, 1995)

Precisamente, uma das teses centrais do artigo Narradores de Javé e narrativas de professores: Espaço, tempo e identidade (Guimarães \& Guimarães, 2011) é que "os relatos, as narrativas dos alunos na sala de aula nos possibilitam analisar as relações entre o conhecimento e a vida humana, entre a educação e a cultura no espaço e no tempo" (p. 264). Para essas autoras, as potencialidades das narrativas resultam úteis na formação educativa, já que as experiências - diálogos - de histórias individuais e coletivas têm saberes que integram uma memória social, uma identidade. Não obstante, uma das perguntas que Guimarães e Guimarães (2011) propõem para reflexão é, especificamente, a de como ensinar e aprender os conceitos de espaço, de tempo e de identidade, no processo de formação educativa, com o propósito de formar novas gerações, uma vez que esses aspectos geográficos, históricos, de memória social e de cultura estão implícitos no diálogo entre os professores e os alunos. São, em verdade, universos infinitos. Com base no filme brasileiro Narradores de Javé (Catani \& Caffé, 2003), vislumbram-se as narrativas como uma opção para o ensino e a 
aprendizagem desses conceitos de espaço, de tempo e de identidade. O filme retrata o problema que os moradores de uma cidade chamada Javé enfrentam ao descobrirem que ela será submersa pelas águas de uma represa. Os moradores não foram indenizados, nem ao menos avisados, porque não possuíam as escrituras das terras. Eles descobrem que o local poderia ser preservado se fosse considerado um patrimônio histórico. Decidem, então, escrever a história de Javé, mas somente uma pessoa em toda a cidade sabia escrever.

Uma das citações mais significativas dessa leitura foi a que contrasta vida e morte: "Javé é inundada e o povo sai em retirada. A perda do lugar implica a perda da própria identidade, dos vínculos sociais, da vida e dos mortos" (Guimarães \& Guimarães, 2011, p. 263). Essa citação é enigmática porque se vincula com a noção de silêncio mencionada nos primeiros parágrafos deste texto, dado que as abordagens teóricas e metodológicas na investigação se centraram unilateralmente no estudo da vida, por assim dizer, mas pouco se aprofundou em sua contraparte: a morte, o silêncio, o estado em que um investigador encontra a realidade antes de estudá-la. Contudo, entende-se que esse dualismo, inseparável, encontra mutuamente respostas de um a outro, quer dizer, de alguma maneira decifra-se o silêncio ou a morte ao investigar o diálogo plurilíngue dos sujeitos por meio das narrativas.

A propósito de vida e de morte, Benjamin (1985) menciona que "o narrador não está de fato presente entre nós, em sua atualidade viva" (p. 197). Refere-se à noção de distanciamento - temporal e espacial - como uma exigência no exercício narrativo e na posição de observadores. Essa distância talvez seja, metaforicamente, ser morto entre os vivos, ser silêncio. No entanto, Benjamin (1985) enfatiza que o maior problema da narrativa e dos narradores não é esse distanciamento em si mesmo, mas a perda da capacidade de intercâmbio de experiências, que é a sua fonte de vida. Assim, concebe-se a narrativa como um reino histórico. Qual é, então, o espírito da narrativa na investigação? Por um lado, a investigação narrativa parece cunhar o plausível, aquilo que poderia ser aceitável para interpretar uma realidade específica no trabalho científico. Por outro lado, a narrativa cunhou, tradicionalmente, o conceito do verossímil, ou seja, aquilo que poderia ser crível como ficção. O plausível e o verossímil são duas noções que devem considerar-se para diferenciar entre fazer ciência e fazer literatura. 
Ao aprofundar o conceito de experiência de Benjamin (1985), que considera uma prática em baixa em nosso mundo, Larrosa (2002) repisa a importância de definir dita palavra e identificar os possíveis fatores que provocaram essa pobreza de experiência. Ele concebe a experiência como aquilo que nos acontece ou nos sucede. Considera-se que vale agregar o que nos acontece como sujeitos históricos, ou seja, em um tempo e em um espaço. Os sujeitos modernos formaram-se pela ênfase dos seres humanos do mundo contemporâneo em formar sujeitos informantes ou informados, que opinam como seres individuais, superados pelo fugaz e pela falta de tempo, assim como pelo excesso de trabalho. Tudo isso, em conjunto com a bandeira do progresso, tem favorecido a destruição da experiência (Larrosa, 2002). Que significa, então, ser sujeito histórico no mundo atual em transformação? Ademais, como se concebe o tempo e o espaço para o sujeito moderno? Nesse contexto, resulta valioso recordar uma citação de Guimarães (2006): "o professor é uma pessoa, o aluno é uma pessoa" (p. 138). Isso nos convida à reflexão sobre o sujeito moderno e vale a pena aprofundar, também, a reflexão sobre a palavra pessoa para ampliar este conceito no campo educativo, nos estudos ou nas investigações sobre educação.

Além dos fatores mencionados por Larrosa (2002), causadores da pobreza de experiência, é preciso recordar novamente as ideias de Rogers (1991) sobre o processo de converter-se em pessoa, as quais se complementam com as de Connelly e Clandinin (1995), que afirmam que só podemos viver as histórias que lemos ou vivemos. Essa perspectiva é necessária para a discussão proposta neste trabalho, pelo fato de levar em consideração a visão da psicologia para o processo de compreensão e de assimilação, sobretudo porque a própria dinâmica do sujeito moderno, em uma suposta era progressista, impede o indivíduo de, psicologicamente, descobrir-se a si mesmo, e, ao não poder fazê-lo, também se torna incapaz de assimilar-se a si mesmo como sujeito histórico. Somos essa dimensão psicológica e, diante da incapacidade do sujeito de descobrir-se a si mesmo, é impossível compreender-se e interpretar-se por meio da experiência.

Considerando a conceção de educação de Connelly e Clandinin (1995), como um processo de construção e reconstrução de histórias, tanto pessoais como sociais, a importância teórica da investigação narrativa consiste em aportar ideias da experiência humana vivida ao campo educativo, 
quer dizer, aplicáveis na experiência educativa. Nesse preciso contexto, argumentam tais autores, o valor central dessa linha de investigação é a geração de temas novos sobre a relação entre teoria e prática no ensino e na aprendizagem (Connelly \& Clandinin, 1995). As narrativas que se constroem nas práticas educativas revelam, comenta Guimarães (2006), uma confrontação múltipla de identidades, de uma perspetiva histórica e cultural. O ser humano se faz humano na relação com os outros seres humanos e a narrativa oral e a escrita permeiam as experiências vividas, porque são instrumentos que possibilitam experiências em níveis muito profundos da complexa subjetividade humana.

\section{Analogia entre as reflexões da investigação educativa e o conto $O$ livro de areia}

Em continuação, será, neste item, discutida a analogia entre as reflexões da investigação educativa referidas nos parágrafos anteriores e o conto O livro de areia, de Borges (2012). Foi mencionado esse emblemático conto hispano-americano em razão da conceção que o autor revela sobre tempo e espaço, embora seja em termos de ficção. A narrativa se desenvolve em torno de um estranho vendedor de bíblias que se apresenta a um colecionador de livros religiosos para oferecer-lhe um exemplar distinto, de páginas únicas que, uma vez vistas e lidas, não voltam a aparecer diante dos olhos de ninguém. Trata-se de tempos e espaços infinitos refletidos em cada página, palavra e símbolo desse livro incomum. Borges questiona a infinitude de um tempo e de um espaço determinados, a infinitude superando toda compreensão e interpretação dos homens sobre sua própria realidade. $\mathrm{O}$ personagem, comprador do livro, descreve-o como monstruoso. Esse fato pode ser interpretado como um reflexo da incapacidade dos seres humanos de capturar, retratar ou compreender, pelo menos, uns instantes do espaçotempo de seu mundo, de seu contexto. No final do conto, nota-se a quase loucura do dono do livro, acostumado apenas ao finito de sua vida cotidiana, incapaz de conviver com tudo o que não tem princípio nem fim.

Escolheu-se trazer à luz neste trabalho O livro de areia (Borges, 2012) porque representa uma metáfora das limitações da investigação narrativa, e, por isso, é conveniente lembrar novamente os termos o plausível e o verossímil; igualmente, rememorar o conceito de plurilinguismo de Bakhtin 
(1982) e o caráter plurivocal mencionado por Connelly e Clandinin (1995), já que se pode conceber como limitante a pureza dos resultados ou achados dos múltiplos - ou infinitos - espaços e tempos envoltos nos saberes sociais e identidade dos alunos e professores em formação, quando se utiliza essa linha de trabalho para indagar sobre a prática educativa. Desse modo se explica a importância da leitura teórica para a articulação do lógico e do real:

A ciência, como modalidade de conhecimento, só se processa como resultado de articulação do lógico com o real, do teórico com o empírico. Não se reduz a um mero levantamento e exposição de fatos ou a uma coleção de dados. Estes precisam ser articulados mediante uma leitura teórica. Só a teoria pode caracterizar como científicos os dados empíricos. Mas, em compensação, ela só gera ciência se estiver articulando dados empíricos. (Severino, 2002, p. 70)

Ademais, não se deve esquecer que o objetivo da investigação qualitativa jamais foi produzir verdades, pois essa produção de verdades inabaláveis corresponde por tradição ao que é defendido pelo paradigma positivista. Evidentemente, menciona Gatti (2007), uma das características da investigação é sempre ter uma margem de incerteza, porque, para os investigadores, não existem as verdades absolutas ou definitivas, mas uma possível síntese com plausibilidade e consistência de condições ou circunstâncias específicas que são lidas mediante teorias e métodos que os mesmos investigadores escolhem. Dessa maneira, a teoria na investigação educativa é uma forma de entender o mundo e, por isso, toda a investigação se fundamenta em uma orientação teórica determinada (Bogdan \& Biklen, 1994).

Em síntese, a experiência, em que se acha implicitamente o diálogo social e plurilinguista (Connelly \& Clandinin, 1985; Guimarães \& Guimarães, 2011; Larrosa, 2002), é o eixo principal da investigação narrativa, pois é a maneira como os sujeitos compreendem e interpretam as relações humanas e a memória social (Benjamin, 1985; Connelly \& Clandinin, 1995; Gatti, 2007; Guimarães \& Guimarães, 2011; Larrosa, 2002), considerando que o objeto da ciência é a construção de uma possibilidade de compreensão da natureza e experiência humanas diante de um mundo com aparência caótica (Connelly \& Clandinin, 1995; Gatti, 2007). Portanto, as narrativas ou os relatos têm contribuições a dar para o ensino e a aprendizagem na formação educativa dos sujeitos nas salas de aulas, porque permitem a análise das relações entre o conhecimento e a vida humana, entre educação e cultura, entre espaço e 
tempo e entre teoria e prática educativas (Connelly \& Clandinin, 1995; Guimarães \& Guimarães, 2011).

A investigação narrativa também é uma fonte de experiência, na medida em que a utilizamos como sujeitos históricos para fazer frente ao individualismo gerado pelo progressismo - doutrina política ligada ao positivismo - e sua aspiração a um sujeito moderno, alienado, incapaz de compreender, interpretar e confrontar seu próprio tempo e espaço de múltiplas identidades, de uma perspectiva histórica e cultural (Connelly \& Clandinin, 1995; Larrosa, 2002). Essa capacidade da investigação narrativa é útil para a formação educativa na teoria e na prática como ensino e aprendizagem da identidade e das relações humanas, também para lograr transformações sobre o próprio tempo e o espaço, possivelmente para combater o sofrimento e a pobreza humana, porque, precisamente, esse é o objetivo dos investigadores do século XIX, o de impulsionar a investigação qualitativa (Bogdan \& Biklen, 1994).

Mas combater o sofrimento e a pobreza humana não é uma tarefa simples. A própria característica subjetiva das várias vozes sociais da investigação narrativa, como ciência, exige uma leitura teórica em conjunto com dados empíricos, uma vez que a escolha de uma maneira de entender o mundo se torna imprescindível para a compreensão e interpretação das histórias individuais e sociais dos sujeitos estudados. Somente desse modo é possível conceber uma transformação articulada entre o lógico e o real. Essa metáfora da incapacidade dos seres humanos de apropriar-se de um tempoespaço determinados, refletida em $O$ livro de areia, não é em si monstruosa, mas comovedora, pois, ainda que se possa apropriar de um pedaço do tempo e do espaço de nossa realidade, o mundo em transformação gera a infinitude do tempo e do espaço.

Neste momento da reflexão é necessário voltarmos à ilustração de Flammarion (1888/2017) porque é possível vislumbrar no missionário dessa obra sua melancolia por um sonho talvez inalcançável: poder capturar e compreender todos os tempos e todos os espaços - desconhecidos e perdidos ainda - que habitam em nós. 


\section{Considerações finais}

Basta verificar a quantidade de publicações derivadas de pesquisas quantitativas, comparando com as pesquisas qualitativas, que logo se pode compreender a inquietude, com relação aos resultados das pesquisas qualitativas, dos investigadores e de todos aqueles que esperam por respostas válidas, prometidas pelos pressupostos da ciência positivista. A tradição positivista da ciência ainda predomina, o desejo de aplicabilidade de novas descobertas científicas no campo educacional cresce a cada dia. Há um crescimento impulsionado pela esperança em melhorar a qualidade do ensino, mas também é motivado pela falta de compreensão e aceitação dos contornos não muito definidos da pesquisa qualitativa, cujo caráter é subjetivo e, por esta razão, apreende o objeto de estudo em permanente mudança. Os resultados abertos e as inesgotáveis interpretações que os cientistas podem oferecer pelo viés do paradigma da pesquisa qualitativa desconfortam aqueles que precisam de respostas imediatas.

Se, num passado distante, os seres humanos estavam satisfeitos com suas crenças, na modernidade abandonaram sua fé e a substituíram por um modelo rígido de produção do conhecimento. Hoje, reconhecendo a crise de conceitos, os seres humanos contemporâneos estão divididos e em contradição consigo mesmos, dada a diversidade de caminhos que indicam diferentes rotas para um mesmo objeto; estão fadados a buscar a calmaria que nunca conquistaram engendrados nas armadilhas da dúvida e nas pistas que eles próprios produzem ao construir suas próprias narrativas.

Diz nossa epígrafe "Quantos silêncios, quantas histórias, quantos universos ainda perdidos" porque existe um rosto oculto na investigação narrativa que anseia, em silêncio, compreender o infinito em nós mesmos. As realidades estudadas pelos pesquisadores da investigação narrativa são uma metáfora de $O$ livro de areia porque este reflete páginas, palavras e símbolos únicos que, uma vez vistos e lidos, não voltam a aparecer diante dos olhos de ninguém, tal como sucede com as experiências vividas pelos sujeitos que se resgatam nas investigações narrativas.

Capturar a experiência vivida em narrativas possibilita o entendimento e a interpretação dos níveis mais profundos da complexa subjetividade humana. Essas narrativas que se constroem na prática educativa revelam 
uma confrontação existencialista em que os sujeitos se elegem a si mesmos em um tempo e em um espaço por meio da palavra para construir mundos humanos e sociais.

A investigação narrativa, com todos seus espaços e todos seus tempos, se converte em uma metodologia que propicia uma rica geração de dados na investigação de natureza qualitativa. Permite que os sujeitos experimentem o mundo por meio de um diálogo entre a memória e a identidade, entre silêncios e histórias, entre essas realidades que estão mortas e que somente tomam vida quando são mediadas pelos pesquisadores, de maneira irrepetível, assim como ocorria com as páginas de O livro de areia.

Estamos acostumados ao finito, à vida quotidiana, à nossa incapacidade comum de não conviver com tudo o que não tem princípio nem fim, quiçá por medo de nos descobrir ou de nos eleger como sujeitos históricos, de não encarar esse rosto oculto e infinito de que todos nós fazemos parte. Quantas histórias, quantos universos ainda perdidos e que, se nos aprofundássemos neles, na prática educativa, nos permitiriam descobrir infinitas possibilidades para a educação dos seres humanos.

\section{Referências}

Bakhtin, M. M. (1982). Estética de la creación verbal. México: Siglo Veintiuno Editores.

Benjamin, W. (1985). O narrador. In W. Benjamin, Obras Escolhidas. Vol. I: Magia e técnica, arte e política (pp. 197-221). São Paulo: Brasiliense.

Bogdan, R., \& Biklen, S. (1994). Investigação qualitativa em educação. Uma introdução à teoria e aos métodos. Porto: Porto Editora.

Borges, J. L. (2012). El libro de arena. México: Alianza.

Catani, V. (Produtora), \& Caffé, E. (Realizadora). (2003). Narradores de Javé [Filme]. Brasil: Bananeira Filmes.

Connelly, F. M., \& Clandinin, D. J. (1995). Relatos de experiencia y investigación narrativa. In J. Larrosa, R. Arnaus, V. Ferrer, N. Pérez de Lara, F. M. Connelly, D. J. Clandinin, \& M. Greene, Déjame que te cuente. Ensayos sobre narrativa y educación (pp. 11-59). Barcelona: Laertes.

Flammarion, C. (1888/2017). L'atmosphère: Météorologie populaire [1888]. Bibliothèque Nationale de France. Disponível em: http://gallica.bnf.fr/ark:/12148/ bpt6k408619m (consultado em janeiro de 2017). 
Gatti, B. (2007). A construção da pesquisa em educação no Brasil. Brasília: Líber Livro Editora.

Guimarães, S. (2006). Aprender a contar, a ouvir, a viver: As narrativas como processo de formação. In I. Alencastro (Org.), Técnicas de ensino. Novos tempos, novas configurações (pp. 137-163). Campinas: Papirus.

Guimarães, S., \& Guimarães, I. (2011). Narradores de Javé e narrativas de professores: Espaço, tempo e identidade. In M. Silva \& A. F. Ramos (Orgs.), Ver História. O ensino vai aos filmes (pp. 247-265). São Paulo: Hucitec.

Larrosa, J. (2002). Notas sobre a experiência e o saber da experiência. Revista Brasileira de Educação, 19, 20-28.

Rogers, C. (1991). El proceso de convertirse en persona. Mi técnica terapéutica. Barcelona: Paidós.

Santo Agostinho (1973). Confissões. De magistro (Do mestre). São Paulo: Editora Abril.

Severino, A. J. (2002). Pós-graduação e pesquisa: O processo de produção e de sistematização do conhecimento no campo educacional. In L. Bianchetti \& A. M. N. Machado (Orgs.), A bússola do escrever (pp. 67-87). São Paulo: Cortez/Editora da UFSC. 


\title{
UNIVERSES OF KNOWLEDGE. REFLECTIONS ON NARRATIVE RESEARCH IN EDUCATION
}

\begin{abstract}
This text aims to offer the reader some notes about concepts involving the theme of narrative research in education and in qualitative research. When discussing this mode of doing research, there are always doubts about its validity, generated by a strong positivist tradition that prevails since the birth of the scientific method. With the intention to deepen the discussion on the nature of qualitative research, of an educational and narrative nature, this work is based on literary analysis and on authors who problematize the terms experience, time, space, word and narrative research. A reflection on the methodological qualities of narrative research is made in the conclusions, as a qualitative methodology that makes possible a rich generation of data for understanding and interpreting deeper levels of the complex human subjectivity and of the educative practice.
\end{abstract}

Keywords

Experience; Time-Space; Word; Narrative research

\section{UNIVERSOS DEL CONOCIMIENTO. REFLEXIONES SOBRE LA INVESTIGACIÓN NARRATIVA EN EDUCACIÓN}

Resumen

Este texto tiene como objetivo ofrecer al lector algunas anotaciones de los conceptos relacionados con la investigación narrativa en educación y en la investigación cualitativa. Al discutir esta modalidad de hacer investigación, hay siempre dudas con respecto a su validez, esto debido a la fuerte tradición positivista que ha predominado desde el nacimiento del método científico. Con la intención de profundizar en la discusión sobre la naturaleza de la investigación cualitativa, educativa y narrativa, este trabajo se apoya en 
autores que problematizan los términos experiencia, tiempo, espacio, palabra e investigación narrativa, a partir de la investigación y de la literatura. En las conclusiones se hace una reflexión sobre la investigación narrativa como un giro metodológico cualitativo que posibilita una rica generación de datos para el entendimiento y la interpretación de niveles más profundos de la compleja subjetividad humana y de la práctica educativa.

Palabras-clave

Experiencia; Tiempo-Espacio; Palabra; Investigación narrativa

Recebido em abril 2017

Aceite para publicação em outubro 2017

i Facultad de Artes, Universidad Autónoma de Baja California/ UABC, México.

ii Faculdade de Educação, Universidade Federal de Uberlândia/ UFU, Brasil.

Toda a correspondência relativa a este artigo deve ser enviada para: Gabriela Cruz Vásquez, UABC, Facultad de Artes, Blvd. Zertuche y Blvd. de los Lagos, s/n, Valle Dorado, Ensenada, Baja California, México. E-mail: cruz.gabriela@uabc.edu.mx 